\title{
Obstructive sleep apnea: A case report on uvulopalatopharyngoplasty and tongue reduction as a first line treatment modality in an underprivileged economic
} status

\author{
Dayaratna J1* Nisahan $\mathrm{B}^{2}$, Wijesinghe $\mathrm{S}^{3}$, Peranantharajah $\mathrm{T}^{4}$ and Samarasinghe $\mathrm{B}^{5}$ \\ ${ }^{1}$ Registrar in Medicine, Teaching Hospital, Jaffna, Sri Lanka \\ ${ }^{2}$ Senior registrar in Medicine, Teaching Hospital, Jaffna, Sri Lanka \\ ${ }^{3}$ Consultant Oral \& Maxillofacial Surgeon, Teaching Hospital, Jaffna, Sri Lanka \\ ${ }^{4}$ Consultant Physician in medicine, Teaching Hospital, Jaffna, Sri Lanka \\ ${ }^{5}$ Consultant Respiratory Physician, Teaching Hospital, Jaffna, Sri Lanka
}

\begin{abstract}
Obstructive sleep apnea (OSA) is one of the emerging non-communicable health hazards with high rates of morbidity and mortality. It's a highly prevalent condition affecting $4 \%$ of middle aged men and $2 \%$ of middle aged women in developed countries [1]. OSA may result in various conditions including morbid obesity [2], structural upper air way abnormalities etc. It may be the underlying cause for the development of hypertension, congestive heart failure, pulmonary hypertension, stroke and myocardial infarction. Currently there are several medical and surgical management strategies for the management of OSA. We report a 56-year-old morbid obese male who was successfully managed with surgical procedure, in setting of poor economic status.
\end{abstract}

\section{Introduction}

Sleep apneas include a spectrum of disorders ranging from simple snoring, central apnea disorders to OSA. Sleep illnesses and there complications cause major health and economic burden for developed and developing nations. Excessive sleepiness during daytime is the main symptom at presentation. It may be diagnosed opportunistically while treating conditions such as congestive cardiac failure (CHF), diabetes mellitus (DM), Myocardial infarction and stroke etc. OSA is a highly prevalent health care issue, and around 18 million suffer from it in recent years in United States. Treatment modalities for OSA are readily evolving and comprise medical methods including continuous positive airway pressure (CPAP), mandibular advancement devices and surgical methods such as Uvulopalatopharyngoplasty [3].

\section{Case report}

We report a 56 year old male with a body mass index (BMI) of 36 , who was on treatment for type $2 \mathrm{DM}$, ischemic heart disease, hypertension (HT) and chronic obstructive pulmonary disease (COPD) present with shortness of breath for 3 months duration. His DM and HT were well under control, and he did not have any recent chest pains. He had good control of his COPD with adherences to inhalers.

On admission to ward he was dyspneic with a respiratory rate of around $20 \mathrm{~min}$. He was centrally cyanosed and peripheral saturation on room air was $70 \%$ Few rhonchi were heard, and there was no ankle edema. Acute heart failure causing low saturation was excluded with negative troponin I, normal electrocardiography and normal 2D Echocardiography. Chest X ray revealed mild cardiomegaly only.
Arterial blood gas study confirmed mild respiratory acidosis due to $\mathrm{CO}_{2}$ retention. Full blood report, serum electrolytes, renal function tests, liver function and inflammatory markers all were within normal limits. OSA was suggested by significant result obtain from Epworth sleep scale (score 16/24) and confirmed by polysomnography. Apnea/ hypopnea index (AHI) was 34 which signified sever OSA.

Oxygen supplementation with face mask did not improve his breathing difficulty as well as peripheral saturation. Dietician referral made and food plan was implemented to reduce his body weight. He was offered the option of CPAP ventilation, where he was not in a financial state to obtain the device. Oral \& Maxillofacial (OMF) team involved actively and offered uvulopalatopharyngoplasty (UPPP) and tongue reduction, as a first line treatment (Figures 1 and 2). He gain good outcome following OMF surgery with achieving 93\% peripheral saturation in room air and he had marked improvement in his symptoms at review at one month post-surgery.

\section{Discussion}

OSA is a major health care problem in the United States of America and other develop counties with high burden to the economy.

Correspondence to: Jagath Dayaratna, Registrar in Medicine, Teaching Hospital, Jaffna, Sri Lanka, Tel. +94718663548, E-mail: jagathdayaratna@yahoo.com

Key words: obstructive sleep apnea, morbid obesity, non-communicable diseases, uvulopalatopharyngoplasty

Received: January 04, 2018; Accepted: January 22, 2018; Published: January 24, 2018 


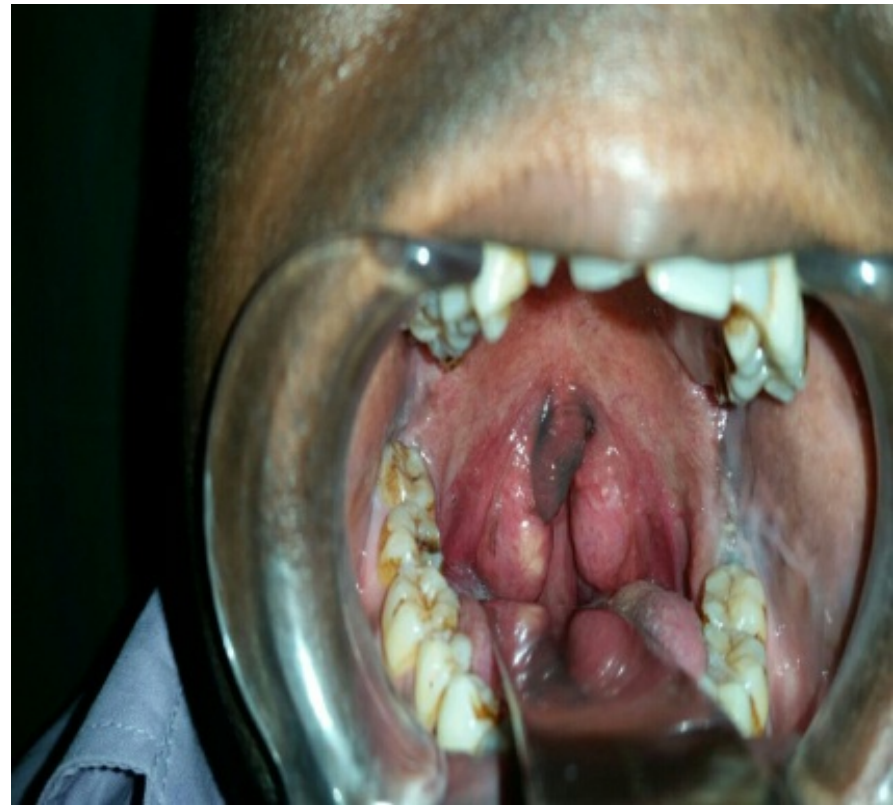

Figure 1. Prior to surgery.

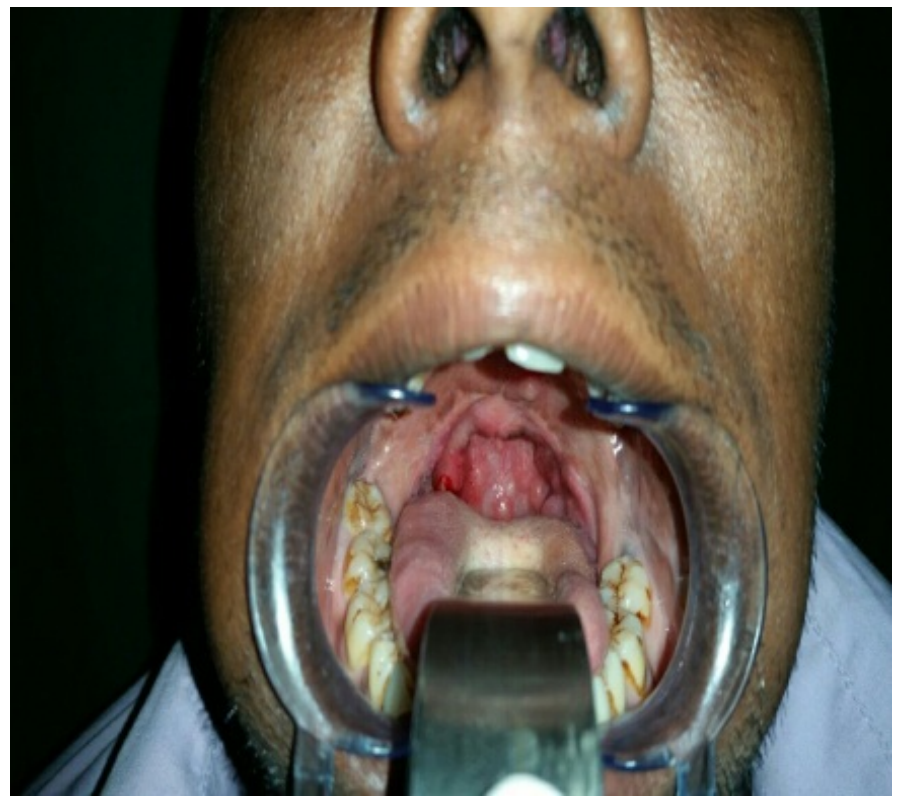

Figure 2. Following surgery.

Developing countries such as Sri Lanka also face increasing prevalence of obesity and non-communicable disease due to urbanization, sedentary life style and poor diet. OSA is also increasingly diagnosed in our clinical practice due to increasing specialized centers throughout the country. It causes increase rates of morbidity and mortality as it's directly related to development of pulmonary hypertension, heart failure, Type $2 \mathrm{DM}$ and many other health hazards. It's increasingly found to be the underlying cause for significant number of road traffic accidents and cause low productivity of workforce.

The pathophysiology of OSA is due to repetitive narrowing or collapse of the pharyngeal airway during sleep. The underlying causes are multifactorial and may vary considerably between individuals. High level of vigilance is needed from health care professionals in early identification of patients with OSA or risk of developing OSA to prevent long and short term complications. Specialty of sleep medicine is developing in a very high pace with the introduction of new modalities of diagnosis and treatment options such as Hypoglossal nerve stimulating devices for the management of OSA. Conservative medical management options are the standard first line treatment for OSA, even though some patients fail to gain good outcome due to various reasons. Medical management of OSA by noninvasive ventilator (NIV) methods such as CPAP is not feasible to majority of patients in developing nations due to low income and unavailability of resources.

Operative procedures such as maxillomandibular advancement, pharyngeal surgeries such as UPPP, laser assisted uvulopalatoplasty (LAUP), and radiofrequency ablation, as well as multi-level and multi-phased procedures in managing OSA had been well establish with good outcome [4]. The successfulness of the surgical manures mainly depends on palate position, tonsil size, and body mass index [5]. Surgical management for OSA might be more appropriate than the stranded initial medical management in the back ground of poor resource setting as well as if the patient is intolerant to NIV.

\section{Conflict of interest}

We declare that we have no conflict of interest.

\section{Funding}

This case report received no specific grants from any funding agency in the public, commercial or not-for-profit sectors.

\section{References}

1. Young T, Palta M, Dempsey J, Skatrud J, Weber S, et al. (1993) The occurrence of sleep-disordered breathing among middle-aged adults. N Engl J Med 328: 1230-1235. [Crossref]

2. " 2015 Pocket Guide to Large Truck and Bus Statistics." Federal Motor Carrier Safety Administration U.S. Department of Transportation. National Transportation Library, April 2015.

3. Lauretano AM (2000) Uvulopalatoplasty using laser-assisted techniques. Operative Techniques in Otolaryngology Head and Neck Surgery 11: 7-11.

4. Surgical Modifications of the Upper Airway for Obstructive Sleep Apnea in Adults: A Systematic Review and Meta-Analysis. Sean M. Caples, DO; James A. Rowley, MD Jeffrey R. Prinsell, DMD, MD; John F. Pallanch, MD; Mohamed B. Elamin, MBBS; Sheri G. Katz, DDS; John D. Harwick, MD https://americansleepandbreathingacademy. com/wp-content/uploads/2015/09/Review_SurgicalModificationsOSA.pdf)

5. Friedman M, Ibrahim H, Bass L (2002) Clinical staging for sleep-disordered breathing Otolaryngol Head Neck Surg 127: 13-21. [Crossref]

Copyright: (C)2018 Dayaratna J. This is an open-access article distributed under the terms of the Creative Commons Attribution License, which permits unrestricted use, distribution, and reproduction in any medium, provided the original author and source are credited. 